\title{
Ontogeny of intestinal epithelial innate immune responses
}

\author{
Mathias W. Hornef ${ }^{1,2 *}$ and Marcus Fulde ${ }^{1 *}$ \\ 1 Institute for Medical Microbiology and Hospital Epidemiology, Hannover Medical School, Hannover, Germany \\ 2 Institute of Medical Microbiology, RWTH University, Aachen, Germany
}

Edited by:

Tobias R. Kollmann, University of

British Columbia, Canada

\section{Reviewed by:}

Urszula Krzych, Walter Reed Army

Institute of Research, USA

Nejat K. Egilmez, University of

Louisville, USA

\section{*Correspondence:}

Mathias W. Hornef, Institute for Medical Microbiology, RWTH

University, Pauwelsstrasse 30,

Aachen 52074, Germany

e-mail:mhornef@ukaachen.de;

Marcus Fulde, Institute for Medical

Microbiology and Hospital

Epidemiology, Hannover Medical

School, Carl-Neuberg Street 1,

Hannover D-30625, Germany

e-mail: fulde.marcus@

mh-hannover.de
Emerging evidence indicates that processes during postnatal development might significantly influence the establishment of mucosal host-microbial homeostasis. Developmental and adaptive immunological processes but also environmental and microbial exposure early after birth might thus affect disease susceptibility and health during adult life. The present review aims at summarizing the current understanding of the intestinal epithelial innate immune system and its developmental and adaptive changes after birth.

Keywords: neonate, innate immunity, mucosal immunology, pattern recognition receptor, antimicrobial peptide, development, infection, inflammation

\section{INNATE IMMUNE RECEPTOR EXPRESSION BY INTESTINAL EPITHELIAL CELLS}

Epithelial cells line the surface of the intestinal mucosa. Together with the mucus layer, they generate the physical barrier between the largely sterile underlying tissue and the enteric lumen exposed to nutritional antigens, inhabited by a dense and dynamic microbiota and challenged by orally acquired pathogenic microorganisms. In addition, epithelial cells actively contribute to hostmicrobial homeostasis, antimicrobial host defense, and epithelial barrier repair. The presence of microbial organisms is detected by the expression of a variety of different innate immune receptors that survey the apical and basolateral plasma membrane, endosomal compartments, and the cytosol. Expression of members of the Toll-like receptor (TLR) family, such as TLR2, 3, 4, 5, and 9, the nucleotide-binding and oligomerization domain (NOD) receptor 1 and 2 and the helicases retinoic acid inducible gene (RIG-I), and the melanoma differentiation associated gene-5 (MDA5), initiate signal transduction cascades via the NF- $\mathrm{KB}$ pathway, mitogen activated protein (MAP) kinases, and interferon regulatory factors (IRFs), and influence epithelial gene expression (1-3). Inflammasome members such as the NOD receptor-related pyrin domaincontaining NLRPs NLRP3, 6, and NLRC4 activate caspase 1 and facilitate the processing of preformed pro-IL-1 $\beta$ and pro-IL-18 and the release of bioactive cytokines as well as the induction of pyroptosis (4-7). In contrast, NLRP12 appears to inhibit canonical and non-canonical NF- $\mathrm{KB}$ signaling (8). Additionally, cellautonomous mechanisms such as the formation of autophagosomes restrict microbial invasion and mucosal translocation in epithelial cells $(9,10)$. Recent reports have highlighted links between these different pathways. For example, NOD1 and 2 were shown to recruit autophagy-related protein 16-like 1 (ATG16L1) to the site of bacterial entry (11). Also, MyD88-dependent cell stimulation downstream of TLR or IL-1R stimulation was linked to autophagy-dependent antibacterial host defense in epithelial cells $(9,12)$. Although experimental evidence suggests the functional presence of innate immune receptors at the intestinal epithelium, a systematic analysis of epithelial cell specific receptor deficient animals has not been performed. The use of bone marrow chimeric mice on the other hand suffers from the potential radio-resistance of mucosal immune cells and the large diversity of stromal cells.

\section{INNATE IMMUNE SIGNALING DURING ONTOGENY: AGE-DEPENDENT RECEPTOR EXPRESSION AND DOWNSTREAM SIGNALING}

Recent reports suggest significant alterations of epithelial innate immune signaling during ontogeny, i.e., the transition from the protected environment in utero to the microbially and environmentally exposed life after birth. Although only beginning to be understood, the changes in the epithelial innate immune response after birth might significantly contribute to establish a stable life-long host-microbial homeostasis. On the other hand, it may predispose the neonate to certain infectious or inflammatory diseases. Indeed, many pathogens of the neonate host such as group B streptococci, Listeria monocytogenes, or Escherichia coli K1 rarely cause disease in adult individuals. Similarly, necrotizing enterocolitis (NEC), an inflammatory enteric disease of unknown etiology is largely restricted to the population of preterm human neonates. In mice, the observed postnatal alterations in epithelial innate immune signaling are accompanied by significant developmental changes. For example, crypts appear only during 


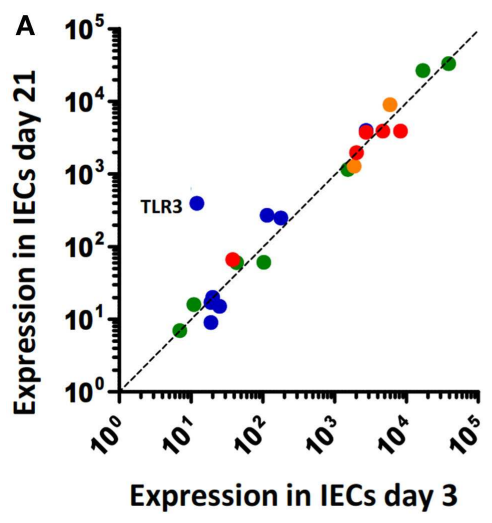

FIGURE 1 | Age-dependent expression of innate immune receptors, signaling, and effector molecules in murine intestinal epithelial cells. (A) Innate immune receptors and inhibitory molecules. TLRs, blue; NLRs, green; RLRs, orange; negative regulators (SIGIRR, A20, PPARy, IRAK-M, IKK2), red.
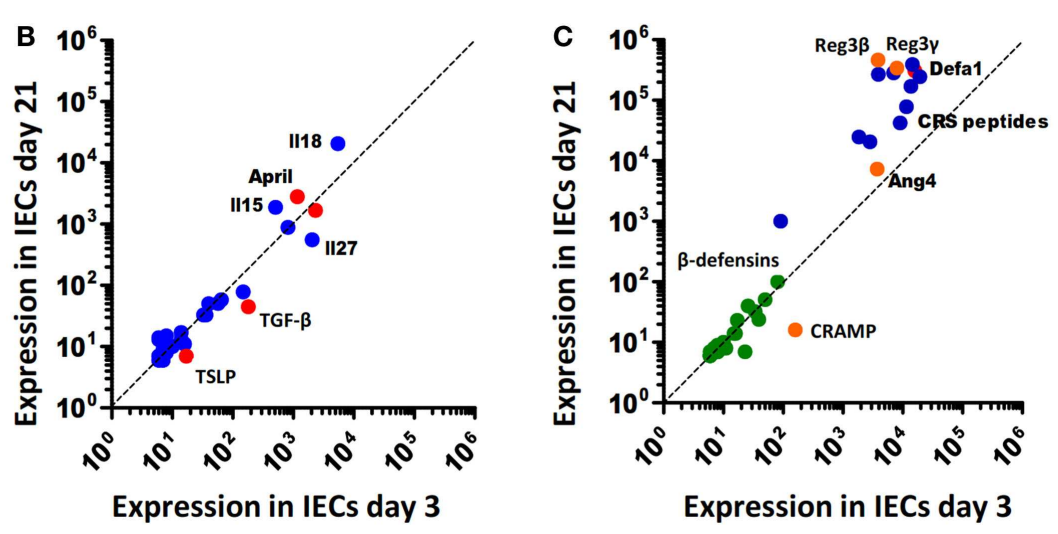

(B) Soluble intermediates: interleukins, blue; epithelial-derived modifiers of myeloid cells, red. (C) Antimicrobial effector molecules: ( $\beta$-defensins, green; CRS peptides, blue; $\alpha$-defensins (Defa), red; Reg3 $\beta / \gamma$, Angiogenin4 (Ang4), and CRAMP, orange. the second week after birth generating the niche for pluripotent $\mathrm{Lgr5}^{+}$stem cells. Stem cells generate the rapidly proliferating pool of so-called transit-amplifying (TA) cells. Enterocyte proliferation within the crypts facilitates the continuous cryptvillus migration and rapid cell turnover in adult animals (13). In the absence of crypts, epithelial proliferation and renewal are markedly diminished in the neonate animal. Cell lines and primary epithelial cells isolated from fetal intestinal tissue express innate immune receptors, respond to microbial ligands, and secrete proinflammatory chemoattractants (14-17). Regulatory mechanisms must, therefore, exist to prevent inappropriate immune stimulation. Hackam and colleagues described downregulation of epithelial TLR4 expression and upregulation of epithelial TLR9 expression prior to birth in mice (18). Since TLR4 mediated epithelial signaling has been associated with mucosal damage (19) and TLR9 stimulation was suggested to dampen inflammation (20), this early adaptive regulation might prepare the fetal epithelium to microbial exposure during the immediate postnatal period. Similarly, our group showed that TLR3 expression in the neonate intestine in mice is low and increases only with weaning (Figure 1A) correlating with the enhanced susceptibility to rotavirus infection during the postnatal period (21). Since TLR3 was shown to amplify the antiviral response by upregulation of the helicases Rig-I and MDA5, low epithelial TLR3 expression in neonate mice might have a broader effect and indirectly also impair the helicase-mediated host response during the postnatal period despite unaltered basal helicase expression levels (22). In contrast to TLR3, members of the NOD-like receptor family, such as NOD1 and 2 but also the inflammasome constituents NLRP1, NLRP3, NALP6, and NALP12 as well as caspase 1 do not underlie any detectable developmental regulation on transcriptional level (Figure 1A). Enhanced expression of the negative regulatory molecules A20, single immunoglobulin IL-1 receptor-related molecule (SIGIRR), interleukin 1 receptor associated kinase (IRAK)-M, and Toll-interacting protein (TOLLIP) has been described in mature human neonatal epithelial cells (23). In mice, however, no major change in their expression level is observed (Figure 1A). Also, immune cell-mediated regulatory mechanisms such as neonatal B cell-derived IL-10 or arginase 2 secretion by newborn $\mathrm{CD} 71^{+}$erythroid cells may dampen the mucosal immune stimulation $(24,25)$. Finally, constituents of the amniotic fluid, colostrum, and breast milk were described to exhibit a negative regulatory effect on mucosal innate immune stimulation during the neonatal and pre-weaning period $(26,27)$. Thus, developmental and environmental mechanisms appear to restrict epithelial stimulation by innate immune receptors during the postnatal period.

On the other hand, exposure to environmental, nutritional, and microbial stimuli after birth appears to induce a protective epithelial response. For example, increased epithelial expression of the pro-inflammatory chemokine Cxcl2 and the NF- $\mathrm{kB}$ induced microRNA miR146-a were observed during the first hours after vaginal delivery in mice $(15,16)$. Also an increase of intestinal TNF mRNA levels was described after birth (28). In human beings, elevated calprotectin levels were measured in healthy term neonates during the first days after birth that reached concentrations comparable to patients with inflammatory bowel disease (29). This stimulation, however, is transient and appears not to be associated with mucosal damage or clinical disease. Postnatal immune activation induces adaptive negative regulatory mechanisms such as downregulation of the TLR signaling molecule IRAK1. Low epithelial IRAK1 protein expression prevents inappropriate transcriptional activation and epithelial cell damage. In addition, it drives a sustained epithelial expression profile that includes genes involved in metabolism, cell survival, and differentiation (16). IRAK1 is involved in the upstream signaling cascade of most TLRs. Only TLR3 signaling occurs completely independent of MyD88/IRAK1 via the adaptor molecule TIR-domain-containing adapter-inducing interferon- $\beta$ (TRIF) (30). TLR3 expression, however, is significantly downregulated in the neonate intestine by the developmental transcriptional repressor B lymphocyteinduced maturation protein (Blimp) 1 as described above (21, 31, 32). IRAK1 protein downregulation and low Tlr3 expression during the postnatal period might explain why deletion of A20, SIGIRR, or TOLLIP does not lead to spontaneous inflammation 
after birth (33-35). It may also cause the reduced pro-IL-18 expression in neonatal epithelial cells and thereby prevent excessive inflammasome-mediated tissue stimulation (Figure 1B). Thus, adaptive mechanisms in addition to the above discussed developmental mechanisms restrict epithelial innate immune activation in the homeostatic neonatal intestine. Following bacterial challenge with enteropathogenic microorganisms, however, the neonatal epithelium is able to respond in a MyD88-dependent fashion (own unpublished observation). The mechanisms that allow stimulation of the neonate epithelium in the event of immediate danger to mount a protective antimicrobial host response have not been investigated but may require contribution from immune cells in the lamina propria.

TLR, NLR, and helicase stimulation but also IL-1 and IL-18 signaling converge at the level of TGF- $\beta$ activated kinase (TAK) 1 , inhibitor of $\kappa \mathrm{B}$ kinase (IKK) $1 / 2$, and NF- $\kappa \mathrm{B}$ essential modulator (NEMO) to induce NF- $\kappa \mathrm{B}$ activation in epithelial cells. NF- $\kappa \mathrm{B}$ signaling inhibits pro-apoptotic pathways and drives the expression of antimicrobial host defense mechanisms. A number of studies have highlighted the protective role of NF- $\kappa \mathrm{B}$ mediated signaling at the epithelium during the postnatal period. For example, $10-15 \%$ of epithelial RelA deficient mice develop intestinal symptoms as early as 2-3 days after birth and succumb to mucosal bleeding both in the small and large intestine before weaning (36). Also, asymptomatic RelA deficient neonates exhibit reduced expression of anti-apoptotic and antimicrobial effector molecules. Similarly, enterocyte-specific TAK1 deficient mice develop spontaneous intestinal inflammation and epithelial apoptosis at the time of birth (28). Surprisingly, signs of epithelial apoptosis and inflammation were already observed prior to birth. Both TNF mediated cell stimulation and enhanced susceptibility to reactive oxygen species (ROS) cause mucosal damage in the neonate host $(28,37)$. Similarly, epithelial loss of NEMO or IKK1/2 expression results in mucosal bleeding, epithelial apoptosis, loss of mucosal integrity, and bacterial translocation and finally significant upregulation of pro-inflammatory cytokines during the first weeks after birth. Inflammation is driven by MyD88- and TNF-dependent pathways. Strikingly, loss of epithelial NEMO or IKK1/2 expression altered the colonic mucosa but left the small intestinal tissue largely unaffected (38). No clinical symptoms are observed during the postnatal period in mice expressing a dominant negative MyD88 transgene in the epithelium possibly due to remaining compensatory NF- $\mathrm{B}$ activating pathways. Transgene animals initially gain weight indistinguishable from littermate controls but exhibit enhanced epithelial proliferation and develop spontaneous small intestinal inflammation at 24 weeks after birth (39). Epithelial-specific MyD88 deficient mice show an impaired mucosal barrier formation but no spontaneous inflammation after the postnatal period (40). Dysfunction in both animal models was at least in part explained by reduced expression of enteric antimicrobial peptides (AMPs). Similarly, MyD88-dependent signaling by radioresistant, non-myeloid cells has been shown to provide protection from inflammation in a chemically induced model of colitis via enhanced signaling through the epidermal growth factor receptor (EGFR) (41). In contrast to the strong phenotype of mice impaired in epithelial NF- $\mathrm{B}$ signaling, epithelial-specific deletion of the mitogen activated protein (MAP) kinase p38 results in an only moderate phenotype. Decreased numbers of goblet cells and an enhanced rate of epithelial proliferation were noted in the adult colon in the absence of overt inflammation (42). In addition to NF- $\mathrm{B}$, also the alternative death complex protects from epithelial cell damage early after birth. Lack of intestinal epithelial FADD expression results in epithelial necroptosis with loss of small intestinal Paneth cells and spontaneous inflammation in small and large intestine associated with $50 \%$ mortality prior to weaning. Although the phenotype was rescued in the absence of Rip3 both in small and large intestine, only the colitis was dependent on MyD88 and TNF. Small intestinal inflammation might be the consequence of reduced antimicrobial peptide secretion (43). Thus, although excess immune activation may lead to organ damage, homeostatic innate immune stimulation appears to be required to prevent epithelial cell death, and drive antimicrobial host defense early after birth. The degree and nature of this homeostatic epithelial signaling may well vary during postnatal development and requires further investigations.

\section{"CROSS-TALK" BETWEEN THE EPITHELIUM AND UNDERLYING IMMUNE CELLS}

Epithelial chemokine secretion upon innate immune stimulation induces the recruitment of professional immune cells to help combating infection. Consistently, enhanced epithelial chemokine expression in adult transgene animals leads to increased recruitment of granulocytes and lymphocytes to the lamina propria (42). Epithelial signals also help to orchestrate adaptive immune functions. The secretion of thymic stromal lymphopoietin (TSLP) inhibits DC-derived IL-12 secretion and $\mathrm{T}_{\mathrm{H}} 1$ differentiation (44) and, thus, drives the $\mathrm{T}$ cell-mediated immune response towards $\mathrm{T}_{\mathrm{H}}$ 2. $\mathrm{A}_{\mathrm{H}}$ 2-prone immune response with high IL-4, IL-5, IL13, and IL-10 levels is typical for the neonate host within its anti-inflammatory environment (45). Epithelial TSLP production remains unaltered and the increasing demand for TSLP is provided by breast milk, as recently reported by MacFarlane et al. (46). TGF$\beta$ is another component of breast milk with anti-inflammatory properties (47). But, in contrast to TSLP, epithelial-specific expression of TGF- $\beta$ is age-dependent and significantly more pronounced around birth (Figure 1B). In addition to retinoic acid and TSLP, TGF- $\beta$ is a strong inducer of tolerogenic $\mathrm{CD}_{103}{ }^{+} \mathrm{DCs}$, which, in turn, promote $\mathrm{T}_{\mathrm{REG}}$ maturation (48). $\mathrm{T}_{\mathrm{REG}}$ cells secrete large amounts of anti-inflammatory cytokines, such as Il-10 (49) and, thus, contribute to the $\mathrm{T}_{\mathrm{H}} 2$ biased immune response of the neonate. Furthermore, it is widely accepted that $\mathrm{T}_{\text {REG }}$ cells are directly involved in the development of a life-long protection against allergic disorders, such as asthma and hay fever $(50,51)$. Although, underlying mechanisms are still elusive, significantly higher levels of regulatory $\mathrm{T}$ cells and $\mathrm{T}_{\mathrm{REG}}$-derived interferon (IFN)- $\gamma$ were observed (52).

Epithelial-derived IL-25 recruits intraepithelial lymphocytes and IL-7 and trans-presented IL-15 maintains their presence (53). The expression of IL-15 is only enhanced after weaning (Figure 1B). An underlying reason is unknown but it can be speculated that expression of IL-15 and its trans-presenting receptor IL-15R $\alpha$ by epithelial cells goes along with the development and appearance of its target cells, IL-2R $\beta$ expressing intraepithelial 
intestinal lymphocytes (IELs). Similarly, the negligible epithelial secretion of a proliferation-inducing ligand (April) and B-cellactivating factor (BAFF) that facilitate $\mathrm{T}$ cell-independent IgA production (54) around birth (Figure 1B) most probably relies on the kinetic of B cell homing to the gut mucosa, which starts only after birth (55).

\section{EPITHELIAL INNATE IMMUNE EFFECTOR MOLECULES}

Protective epithelial effector functions include the synthesis of antimicrobial molecules, maintenance of the mucus layer, secretion of signaling intermediates, and an enhancement of epithelial tight junctions and cell turn over to remove infected or damaged cells. The active role of the epithelium appears to be critical also under homeostatic conditions to maintain barrier integrity. Epithelial-specific knockouts that impair cell signaling (28, 38, $39)$, disturb histone acetylation and microRNA function $(56,57)$, reduce apoptosis (43), alter epithelial cell differentiation $(58,59)$ or decrease mucus production (60), and lead to tissue damage and mucosal inflammation. Innate immune stimulation reinforces tight junction expression and regulates the epithelial barrier function (61). Also, epithelium-derived antimicrobial molecules such as Reg $3 \gamma$, defensins or reactive oxygen, or nitrogen species provide direct antibacterial activity $(40,62)$. Effector molecules with antimicrobial and barrier promoting properties support the maintenance of gut homeostasis. The most abundant effector molecules in the intestine are AMPs (63). They significantly influence the microbial composition but also the susceptibility to infection (64). AMPs comprise members of different protein families, including defensins, defensin-like molecules such as cryptdin-related sequence (CRS) peptides, cathelicidins, C-type lectins, such as the regenerative islet-derived proteins $3 \beta$ and $\gamma$ (Reg3 $\beta$ and Reg3 $\gamma$ ), and RNAses, such as angiogenin 4 (Ang4) (65). Defensins are highly cationic peptides with an average length of approximately 30-40 amino acids. They encode for six cysteine residues that form characteristic, intramolecular disulfide bonds, and prevent peptide degradation $(66,67)$. Paneth cells in the small intestine constitute the main reservoir of $\alpha$-defensins (68). $\beta$-defensins are mainly expressed in the colon by absorptive colonocytes. Whereas the genome of mice encodes more than 20 different $\alpha$-defensins (also termed cryptdins in mice), human beings only produce two, human defensing (HD)-5 and HD-6 $(63,69)$. CRS peptides are evolutionary closely related to cryptdins and share a variety of properties such as the generation by Paneth cells as an inactive pro-form (69). In contrast to cryptdins, CRS peptides have the potential to form covalent homo- and heterodimers and, thus, are able to assemble a large number of different peptide molecules (70). The transcription of $\alpha$-defensins and CRS peptides is largely constitutive and not subjective to known environmental signals (71). Release from Paneth cells, in contrast, occurs in response to microbial but also nervous and endogenous mediators $(72,73)$. In contrast to cryptdins, epithelial Reg3 $\beta$ and Reg3 $\gamma$ as well as Ang4 expression is MyD88 dependent and enhanced in the presence of the enteric microbiota or the pro-inflammatory response to environmental or infectious stimuli $(40,74)$. Significant differences in the antimicrobial peptide spectrum exist along the length of the small intestine but also between different mouse strains (75). This fact requires attention, since it has led to the misinterpretation of results by comparing, e.g., insufficiently backcrossed gene animals in the past (76).

\section{THE ANTIMICROBIAL PEPTIDE REPERTOIRE DURING ONTOGENY}

The neonate small intestinal epithelium expresses the cathelicidin cathelin-related antimicrobial peptide (CRAMP) (77). CRAMP exerts antibacterial activity against commensal and pathogenic bacteria in vitro and protects the neonate intestinal mucosa from Listeria monocytogenes, a leading cause of neonatal sepsis and meningitis in newborns. Production of Paneth cell-derived AMPs like cryptdins and CRS peptides only starts approximately day 9 post partum in C57BL/6 mice as shown in Figure 1C, reflecting the delayed appearance of small intestinal Paneth cells during the postnatal period $(77,78)$. Since intestinal epithelial CRAMP expression wanes after the postnatal period this results in a switch in the peptide repertoire and production site from epithelial CRAMP expression in the neonate to Paneth cell-secreted cryptdins and CRS peptides after weaning (Figure 1C). Adult mice deficient for the metalloproteinase (MMP)-7, and, therefore, unable to generate mature cryptdins and CRS peptides show a higher number of Firmicutes and a lower amount of Bacteroidetes in the small intestine (64). Since the transition in nutrition from breast milk to solid food goes along with a reduction of Firmicutes, the specific antimicrobial potential of cryptdins might help to prepare the neonatal intestine for weaning. Also, the lack of Paneth cell-derived defensins in the neonate host might explain the susceptibility of neonate but not adult mice to oral challenge with Shigella flexneri $(79,80)$. Consistently, mice lacking MMP-7 are more susceptible to invasive Salmonella Typhimurium infection and exhibit a reduced ability to clear the bacteria from the small intestine (81). The expression of Reg $3 \beta / \gamma$, and Ang4 is maximal in adult animals (Figure 1C). This may in part be attributable to the low stimulatory potential of the developing enteric microbiota and facilitate early colonization by mainly gram-positive commensal bacteria (82). Importantly, AMPs in adult mice act in concert with the mucus layer overlaying the epithelium both in the small and large intestine. Release by Paneth cells leads to enrichment of cryptdins and CRS peptides in mucus material generating a physico-chemical shield to protect the epithelial surface $(83,84)$. Similarly, also Reg $3 \gamma$ acts to promote the mucus barrier and Reg $3 \beta / \gamma$ and Ang 4 expression was noted in mucus-producing goblet cells $(62,85)$. The neonate intestine displays a reduced mucus layer [(86) and own unpublished observation]. Expression of CRAMP by enterocytes lining the epithelial surface might compensate for the reduced mucus layer to provide protection of the epithelial surface.

In conclusion, developmental and adaptive changes accompany the establishment of mucosal host-microbial homeostasis in the intestine after birth (Figure 2). Although the functional importance of these changes is incompletely understood, the observed mechanisms appear to contribute to the transition from the protected environment in utero to the microbially and environmentally exposed life after birth. A deeper understanding requires further investigations but might ultimately help to explain the development of inflammatory but also metabolic diseases and allow the development of prophylactic and therapeutic strategies. 


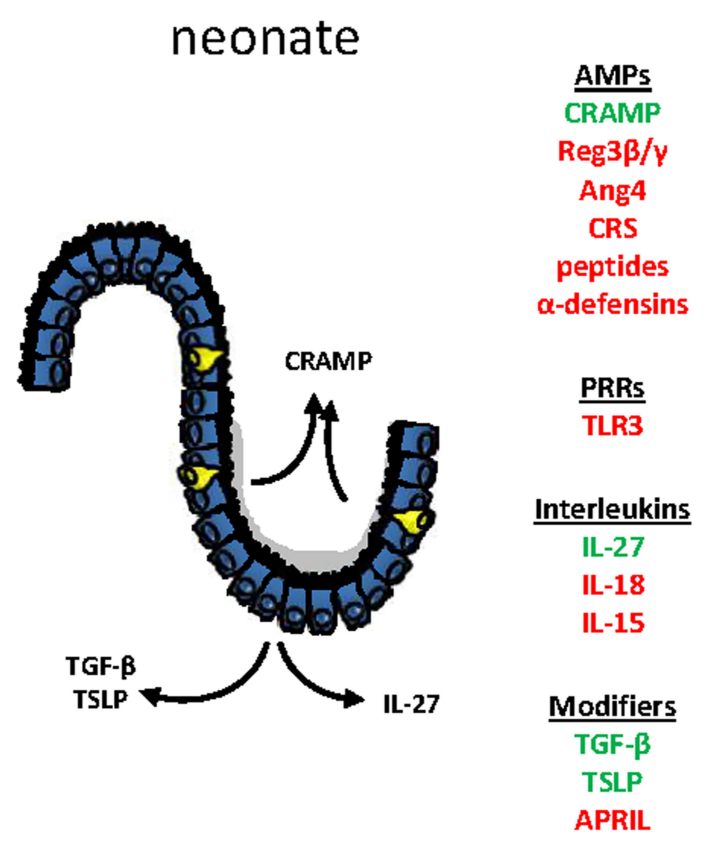

adult

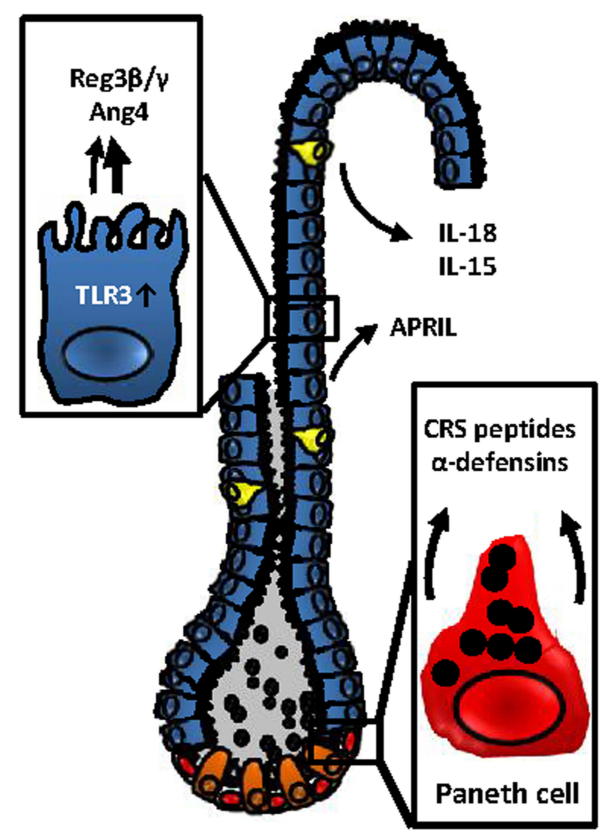

intestinal epithelium. Age-dependently expressed genes are highlighted in green (upregulation in the neonate epithelium) or red (downregulated in the neonate epithelium). molecules expression at the mouse intestinal epithelium. Changes in the epithelial architecture between the murine neonate (left) and adult (right)

\section{ACKNOWLEDGMENTS}

Mathias W. Hornef and Marcus Fulde were supported by the German Research Foundation (Ho2236/8-1), the DFG Priority Program 1656 and 1580 and the Niedersachsen-Research Network on Neuroinfectiology (N-RENNT). Mathias W. Hornef additionally received support from the Collaborative Research Center SFB900 (A4), the Lower Saxony-Israel Found, as well as the Center for Infection Biology (ZIB) and the international research training group (IRTG1273) within Hannover Biomedical Research School (HBRS).

\section{REFERENCES}

1. Philpott DJ, Girardin SE. Nod-like receptors: sentinels at host membranes. Curr Opin Immunol (2010) 22:428-34. doi:10.1016/j.coi.2010.04.010

2. Broquet AH, Hirata Y, Mcallister CS, Kagnoff MF. RIG-I/MDA5/MAVS are required to signal a protective IFN response in rotavirus-infected intestinal epithelium. J Immunol (2011) 186:1618-26. doi:10.4049/jimmunol.1002862

3. Pott J, Hornef M. Innate immune signalling at the intestinal epithelium in homeostasis and disease. EMBO Rep (2012) 13:684-98. doi:10.1038/embor. 2012.96

4. Yeretssian G. Effector functions of NLRs in the intestine: innate sensing, cell death, and disease. Immunol Res (2012) 54:25-36. doi:10.1007/s12026-0128317-3

5. Nordlander S, Pott J, Maloy KJ. NLRC4 expression in intestinal epithelial cells mediates protection against an enteric pathogen. Mucosal Immunol (2014) 7:775-85. doi:10.1038/mi.2013.95

6. Song-Zhao GX, Srinivasan N, Pott J, Baban D, Frankel G, Maloy KJ. Nlrp3 activation in the intestinal epithelium protects against a mucosal pathogen. Mucosal Immunol (2014) 7:763-74. doi:10.1038/mi.2013.94

7. Zambetti LP, Mortellaro A. NLRPs, microbiota, and gut homeostasis: unravelling the connection. J Pathol (2014) 233:321-30. doi:10.1002/path.4357
8. Allen IC, Wilson JE, Schneider M, Lich JD, Roberts RA, Arthur JC, et al. NLRP12 suppresses colon inflammation and tumorigenesis through the negative regulation of noncanonical NF-kappaB signaling. Immunity (2012) 36:742-54. doi:10.1016/j.immuni.2012.03.012

9. Conway KL, Kuballa P, Song JH, Patel KK, Castoreno AB, Yilmaz OH, et al. Atg1611 is required for autophagy in intestinal epithelial cells and protection of mice from Salmonella infection. Gastroenterology (2013) 145:1347-57. doi:10.1053/j.gastro.2013.08.035

10. Randow F, Macmicking JD, James LC. Cellular self-defense: how cellautonomous immunity protects against pathogens. Science (2013) 340:701-6. doi:10.1126/science. 1233028

11. Zhao Y, Alonso C, Ballester I, Song JH, Chang SY, Guleng B, et al. Control of NOD2 and Rip2-dependent innate immune activation by GEF-H1. Inflamm Bowel Dis (2012) 18:603-12. doi:10.1002/ibd.21851

12. Benjamin JL, Sumpter R Jr, Levine B, Hooper LV. Intestinal epithelial autophagy is essential for host defense against invasive bacteria. Cell Host Microbe (2013) 13:723-34. doi:10.1016/j.chom.2013.05.004

13. Clevers H. The intestinal crypt, a prototype stem cell compartment. Cell (2013) 154:274-84. doi:10.1016/j.cell.2013.07.004

14. Bens M, Bogdanova A, Cluzeaud F, Miquerol L, Kerneis S, Kraehenbuhl JP, et al. Transimmortalized mouse intestinal cells $(\mathrm{m}-\mathrm{ICc} 12)$ that maintain a crypt phenotype. Am J Physiol (1996) 270:C1666-74.

15. Lotz M, Gutle D, Walther S, Menard S, Bogdan C, Hornef MW. Postnatal acquisition of endotoxin tolerance in intestinal epithelial cells. J Exp Med (2006) 203:973-84. doi:10.1084/jem.20050625

16. Chassin C, Kocur M, Pott J, Duerr CU, Gutle D, Lotz M, et al. miR-146a mediates protective innate immune tolerance in the neonate intestine. Cell Host Microbe (2010) 8:358-68. doi:10.1016/j.chom.2010.09.005

17. Schwerk J, Koster M, Hauser H, Rohde M, Fulde M, Hornef MW, et al. Generation of mouse small intestinal epithelial cell lines that allow the analysis of specific innate immune functions. PLoS One (2013) 8:e72700. doi:10.1371/journal. pone. 0072700

18. Gribar SC, Sodhi CP, Richardson WM, Anand RJ, Gittes GK, Branca MF, et al. Reciprocal expression and signaling of TLR4 and TLR9 in the pathogenesis 
and treatment of necrotizing enterocolitis. J Immunol (2009) 182:636-46. doi:10.4049/jimmunol.182.1.636

19. Afrazi A, Branca MF, Sodhi CP, Good M, Yamaguchi Y, Egan CE, et al. Toll-like receptor 4-mediated endoplasmic reticulum stress in intestinal crypts induces necrotizing enterocolitis. J Biol Chem (2014) 289:9584-99. doi:10.1074/jbc. M113.526517

20. Katakura K, Lee J, Rachmilewitz D, Li G, Eckmann L, Raz E. Toll-like receptor 9induced type I IFN protects mice from experimental colitis. J Clin Invest (2005) 115:695-702. doi:10.1172/JCI200522996C1

21. Pott J, Stockinger S, Torow N, Smoczek A, Lindner C, Mcinerney G, et al. Age-dependent TLR3 expression of the intestinal epithelium contributes to rotavirus susceptibility. PLoS Pathog (2012) 8:e1002670. doi:10.1371/journal. ppat. 1002670

22. Slater L, Bartlett NW, Haas JJ, Zhu J, Message SD, Walton RP, et al. Co-ordinated role of TLR3, RIG-I and MDA5 in the innate response to rhinovirus in bronchial epithelium. PLoS Pathog (2010) 6:e1001178. doi:10.1371/journal.ppat.1001178

23. Nanthakumar N, Meng D, Goldstein AM, Zhu W, Lu L, Uauy R, et al. The mechanism of excessive intestinal inflammation in necrotizing enterocolitis: an immature innate immune response. PLoS One (2011) 6(3):e17776. doi:10.1371/journal.pone.0017776

24. Zhang X, Deriaud E, Jiao X, Braun D, Leclerc C, Lo-Man R. Type I interferons protect neonates from acute inflammation through interleukin 10-producing $\mathrm{B}$ cells. J Exp Med (2007) 204:1107-18. doi:10.1084/jem.20062013

25. Elahi S, Ertelt JM, Kinder JM, Jiang TT, Zhang X, Xin L, et al. Immunosuppressive CD71+ erythroid cells compromise neonatal host defence against infection. Nature (2013) 504:158-62. doi:10.1038/nature 12675

26. LeBouder E, Rey-Nores JE, Raby AC, Affolter M, Vidal K, Thornton CA, et al. Modulation of neonatal microbial recognition: TLR-mediated innate immune responses are specifically and differentially modulated by human milk. J Immunol (2006) 176:3742-52. doi:10.4049/jimmunol.176.6.3742

27. Good M, Siggers RH, Sodhi CP, Afrazi A, Alkhudari F, Egan CE, et al. Amniotic fluid inhibits Toll-like receptor 4 signaling in the fetal and neonatal intestinal epithelium. Proc Natl Acad Sci U S A (2012) 109:11330-5. doi:10.1073/pnas. 1200856109

28. Kajino-Sakamoto R, Inagaki M, Lippert E, Akira S, Robine S, Matsumoto $\mathrm{K}$, et al. Enterocyte-derived TAK1 signaling prevents epithelium apoptosis and the development of ileitis and colitis. J Immunol (2008) 181:1143-52. doi:10.4049/jimmunol.181.2.1143

29. Kapel N, Campeotto F, Kalach N, Baldassare M, Butel MJ, Dupont C. Faecal calprotectin in term and preterm neonates. J Pediatr Gastroenterol Nutr (2010) 51:542-7. doi:10.1097/MPG.0b013e3181e2ad72

30. Takeda K, Akira S. TLR signaling pathways. Semin Immunol (2004) 16:3-9. doi:10.1016/j.smim.2003.10.003

31. Harper J, Mould A, Andrews RM, Bikoff EK, Robertson EJ. The transcriptional repressor Blimp1/Prdm1 regulates postnatal reprogramming of intestinal enterocytes. Proc Natl Acad Sci U S A (2011) 108:10585-90. doi:10.1073/pnas. 1105852108

32. Muncan V, Heijmans J, Krasinski SD, Buller NV, Wildenberg ME, Meisner S, et al. Blimp1 regulates the transition of neonatal to adult intestinal epithelium. Nat Commun (2011) 2:452. doi:10.1038/ncomms1463

33. Xiao H, Gulen MF, Qin J, Yao J, Bulek K, Kish D, et al. The Toll-interleukin-1 receptor member SIGIRR regulates colonic epithelial homeostasis, inflammation, and tumorigenesis. Immunity (2007) 26:461-75. doi:10.1016/j.immuni. 2007.02.012

34. Vereecke L, Sze M, Mc Guire C, Rogiers B, Chu Y, Schmidt-Supprian M, et al. Enterocyte-specific A20 deficiency sensitizes to tumor necrosis factorinduced toxicity and experimental colitis. J Exp Med (2010) 207:1513-23. doi:10.1084/jem.20092474

35. Maillard MH, Bega H, Uhlig HH, Barnich N, Grandjean T, Chamaillard M, et al. Toll-interacting protein modulates colitis susceptibility in mice. Inflamm Bowel Dis (2014) 20:660-70. doi:10.1097/MIB.0000000000000006

36. Steinbrecher KA, Harmel-Laws E, Sitcheran R, Baldwin AS. Loss of epithelial RelA results in deregulated intestinal proliferative/apoptotic homeostasis and susceptibility to inflammation. J Immunol (2008) 180:2588-99. doi:10.4049/ jimmunol.180.4.2588

37. Kajino-Sakamoto R, Omori E, Nighot PK, Blikslager AT, Matsumoto K, Ninomiya-Tsuji J. TGF-beta-activated kinase 1 signaling maintains intestinal integrity by preventing accumulation of reactive oxygen species in the intestinal epithelium. J Immunol (2010) 185:4729-37. doi:10.4049/jimmunol.0903587
38. Nenci A, Becker C, Wullaert A, Gareus R, Van Loo G, Danese S, et al. Epithelial NEMO links innate immunity to chronic intestinal inflammation. Nature (2007) 446:557-61. doi:10.1038/nature05698

39. Gong J, Xu J, Zhu W, Gao X, Li N, Li J. Epithelial-specific blockade of MyD88dependent pathway causes spontaneous small intestinal inflammation. Clin Immunol (2010) 136:245-56. doi:10.1016/j.clim.2010.04.001

40. Frantz AL, Rogier EW, Weber CR, Shen L, Cohen DA, Fenton LA, et al. Targeted deletion of MyD88 in intestinal epithelial cells results in compromised antibacterial immunity associated with downregulation of polymeric immunoglobulin receptor, mucin-2, and antibacterial peptides. Mucosal Immunol (2012) 5:501-12. doi:10.1038/mi.2012.23

41. Brandl K, Sun L, Neppl C, Siggs OM, Le Gall SM, Tomisato W, et al. MyD88 signaling in nonhematopoietic cells protects mice against induced colitis by regulating specific EGF receptor ligands. Proc Natl Acad Sci U S A (2010) 107:19967-72. doi:10.1073/pnas.1014669107

42. Ohtsuka Y, Lee J, Stamm DS, Sanderson IR. MIP-2 secreted by epithelial cells increases neutrophil and lymphocyte recruitment in the mouse intestine. Gut (2001) 49:526-33. doi:10.1136/gut.49.4.526

43. Welz PS, Wullaert A, Vlantis K, Kondylis V, Fernandez-Majada V, Ermolaeva M, et al. FADD prevents RIP3-mediated epithelial cell necrosis and chronic intestinal inflammation. Nature (2011) 477:330-4. doi:10.1038/nature10273

44. Rimoldi M, Chieppa M, Salucci V, Avogadri F, Sonzogni A, Sampietro GM, et al. Intestinal immune homeostasis is regulated by the crosstalk between epithelial cells and dendritic cells. Nat Immunol (2005) 6:507-14. doi:10.1038/ni1192

45. Lee HH, Hoeman CM, Hardaway JC, Guloglu FB, Ellis JS, Jain R, et al. Delayed maturation of an IL-12-producing dendritic cell subset explains the early Th2 bias in neonatal immunity. J Exp Med (2008) 205:2269-80. doi:10.1084/jem. 20071371

46. MacFarlane TV, Seager AL, Moller M, Morgan G, Thornton CA. Thymic stromal lymphopoietin is present in human breast milk. Pediatr Allergy Immunol (2010) 21(2 Pt 2):e454-6. doi:10.1111/j.1399-3038.2009.00916.x

47. Walker A. Breast milk as the gold standard for protective nutrients. J Pediatr (2010) 156:S3-7. doi:10.1016/j.jpeds.2009.11.021

48. Chen W, Jin W, Hardegen N, Lei KJ, Li L, Marinos N, et al. Conversion of peripheral $\mathrm{CD} 4^{+} \mathrm{CD} 25^{-}$naive $\mathrm{T}$ cells to $\mathrm{CD} 4^{+} \mathrm{CD} 25^{+}$regulatory T cells by TGFbeta induction of transcription factor Foxp3. J Exp Med (2003) 198:1875-86. doi:10.1084/jem.20030152

49. Hadis U, Wahl B, Schulz O, Hardtke-Wolenski M, Schippers A, Wagner N, et al. Intestinal tolerance requires gut homing and expansion of FoxP3+ regulatory $\mathrm{T}$ cells in the lamina propria. Immunity (2011) 34(2):237-46. doi:10.1016/j. immuni.2011.01.016

50. Ege MJ, Mayer M, Normand AC, Genuneit J, Cookson WO, Braun-Fahrländer C, et al. Exposure to environmental microorganisms and childhood asthma. NEngl J Med (2011) 364(8):701-9. doi:10.1056/NEJMoa1007302

51. von Mutius E, Vercelli D. Farm living: effects on childhood asthma and allergy. Nat Rev Immunol (2010) 10(12):861-8. doi:10.1038/nri2871

52. Hinz D, Bauer M, Röder S, Olek S, Huehn J, Sack U, et al. Cord blood Tregs with stable FOXP3 expression are influenced by prenatal environment and associated with atopic dermatitis at the age of one year. Allergy (2012) 67(3):380-9. doi:10.1111/j.1398-9995.2011.02767.x

53. Ma LJ, Acero LF, Zal T, Schluns KS. Trans-presentation of IL-15 by intestinal epithelial cells drives development of CD8alphaalpha IELs. J Immunol (2009) 183:1044-54. doi:10.4049/jimmunol.0900420

54. He B, Xu W, Santini PA, Polydorides AD, Chiu A, Estrella J, et al. Intestinal bacteria trigger $\mathrm{T}$ cell-independent immunoglobulin $\mathrm{A}(2)$ class switching by inducing epithelial-cell secretion of the cytokine APRIL. Immunity (2007) 26:812-26. doi:10.1016/j.immuni.2007.04.014

55. Lundell AC, Rabe H, Quiding-Järbrink M, Andersson K, Nordström I, Adlerberth I, et al. Development of gut-homing receptors on circulating B cells during infancy. Clin Immunol (2011) 138(1):97-106. doi:10.1016/j.clim.2010. 10.003

56. McKenna LB, Schug J, Vourekas A, Mckenna JB, Bramswig NC, Friedman JR, et al. MicroRNAs control intestinal epithelial differentiation, architecture, and barrier function. Gastroenterology (2010) 139(1654-1664):1664e1651. doi:10.1053/j.gastro.2010.07.040

57. Turgeon N, Gagne JM, Blais M, Gendron FP, Boudreau F, Asselin C. The acetylome regulators $\mathrm{Hdacl}$ and $\mathrm{Hdac} 2$ differently modulate intestinal epithelial cell dependent homeostatic responses in experimental colitis. Am J Physiol Gastrointest Liver Physiol (2014) 306:G594-605. doi:10.1152/ajpgi.00393.2013 
58. Guilmeau S, Flandez M, Bancroft L, Sellers RS, Tear B, Stanley P, et al. Intestinal deletion of Pofutl in the mouse inactivates notch signaling and causes enterocolitis. Gastroenterology (2008) 135:849-60. doi:10.1053/j.gastro.2008.05.050

59. Obata Y, Takahashi D, Ebisawa M, Kakiguchi K, Yonemura S, Jinnohara T, et al. Epithelial cell-intrinsic Notch signaling plays an essential role in the maintenance of gut immune homeostasis. J Immunol (2012) 188:2427-36. doi:10.4049/jimmunol.1101128

60. Van der Sluis M, De Koning BA, De Bruijn AC, Velcich A, Meijerink JP, Van Goudoever JB, et al. Muc2-deficient mice spontaneously develop colitis, indicating that MUC2 is critical for colonic protection. Gastroenterology (2006) 131:117-29. doi:10.1053/j.gastro.2006.04.020

61. Cario E, Gerken G, Podolsky DK. Toll-like receptor 2 enhances ZO-1-associated intestinal epithelial barrier integrity via protein kinase C. Gastroenterology (2004) 127:224-38. doi:10.1053/j.gastro.2004.04.015

62. Vaishnava S, Yamamoto M, Severson KM, Ruhn KA, Yu X, Koren O, et al. The antibacterial lectin RegIIIgamma promotes the spatial segregation of microbiota and host in the intestine. Science (2011) 334:255-8. doi:10.1126/science.1209791

63. Bevins CL, Salzman NH. Paneth cells, antimicrobial peptides and maintenance of intestinal homeostasis. Nat Rev Microbiol (2011) 9:356-68. doi:10.1038/ nrmicro2546

64. Salzman NH, Hung K, Haribhai D, Chu H, Karlsson-Sjoberg J, Amir E, et al. Enteric defensins are essential regulators of intestinal microbial ecology. Nat Immunol (2010) 11:76-83. doi:10.1038/ni.1825

65. Gallo RL, Hooper LV. Epithelial antimicrobial defence of the skin and intestine. Nat Rev Immunol (2012) 12:503-16. doi:10.1038/nri3228

66. Ganz T. Defensins: antimicrobial peptides of innate immunity. Nat Rev Immunol (2003) 3:710-20. doi:10.1038/nri1180

67. Lehrer RI. Primate defensins. Nat Rev Microbiol (2004) 2:727-38. doi:10.1038/ nrmicro976

68. Clevers HC, Bevins CL. Paneth cells: maestros of the small intestinal crypts. Annu Rev Physiol (2013) 75:289-311. doi:10.1146/annurev-physiol-030212-183744

69. Huttner KM, Selsted ME, Ouellette AJ. Structure and diversity of the murine cryptdin gene family. Genomics (1994) 19:448-53. doi:10.1006/geno.1994.1093

70. Hornef MW, Putsep K, Karlsson J, Refai E, Andersson M. Increased diversity of intestinal antimicrobial peptides by covalent dimer formation. Nat Immunol (2004) 5:836-43. doi:10.1038/ni1094

71. Putsep K, Axelsson LG, Boman A, Midtvedt T, Normark S, Boman HG, et al. Germ-free and colonized mice generate the same products from enteric prodefensins. J Biol Chem (2000) 275:40478-82. doi:10.1074/jbc.M007816200

72. Rumio C, Sommariva M, Sfondrini L, Palazzo M, Morelli D, Vigano L, et al. Induction of Paneth cell degranulation by orally administered Toll-like receptor ligands. J Cell Physiol (2012) 227:1107-13. doi:10.1002/jcp.22830

73. Stockinger S, Albers T, Duerr CU, Menard S, Putsep K, Andersson M, et al. Interleukin-13-mediated Paneth cell degranulation and antimicrobial Peptide release. J Innate Immun (2014) 6:530-41. doi:10.1159/000357644

74. Hooper LV, Stappenbeck TS, Hong CV, Gordon JI. Angiogenins: a new class of microbicidal proteins involved in innate immunity. Nat Immunol (2003) 4:269-73. doi: $10.1038 /$ ni888

75. Karlsson J, Putsep K, Chu H, Kays RJ, Bevins CL, Andersson M. Regional variations in Paneth cell antimicrobial peptide expression along the mouse intestinal tract. BMC Immunol (2008) 9:37. doi:10.1186/1471-2172-9-37

76. Shanahan MT, Carroll IM, Grossniklaus E, White A, Von Furstenberg RJ, Barner $\mathrm{R}$, et al. Mouse Paneth cell antimicrobial function is independent of Nod2. Gut (2014) 63:903-10. doi:10.1136/gutjnl-2012-304190
77. Menard S, Forster V, Lotz M, Gutle D, Duerr CU, Gallo RL, et al. Developmental switch of intestinal antimicrobial peptide expression. J Exp Med (2008) 205:183-93. doi:10.1084/jem.20071022

78. Bry L, Falk P, Huttner K, Ouellette A, Midtvedt T, Gordon JI. Paneth cell differentiation in the developing intestine of normal and transgenic mice. Proc Natl Acad Sci U S A (1994) 91:10335-9. doi:10.1073/pnas.91.22.10335

79. Fernandez MI, Regnault B, Mulet C, Tanguy M, Jay P, Sansonetti PJ, et al. Maturation of Paneth cells induces the refractory state of newborn mice to Shigella infection. J Immunol (2008) 180:4924-30. doi:10.4049/jimmunol.180. 7.4924

80. Shim DH, Ryu S, Kweon MN. Defensins play a crucial role in protecting mice against oral Shigella flexneri infection. Biochem Biophys Res Commun (2010) 401:554-60. doi:10.1016/j.bbrc.2010.09.100

81. Wilson CL, Ouellette AJ, Satchell DP, Ayabe T, Lopez-Boado YS, Stratman JL, et al. Regulation of intestinal alpha-defensin activation by the metalloproteinase matrilysin in innate host defense. Science (1999) 286:113-7. doi:10.1126/science. 286.5437.113

82. Lehotzky RE, Partch CL, Mukherjee S, Cash HL, Goldman WE, Gardner KH, et al. Molecular basis for peptidoglycan recognition by a bactericidal lectin. Proc Natl Acad Sci U S A (2010) 107:7722-7. doi:10.1073/pnas.0909449107

83. Meyer-Hoffert U, Hornef MW, Henriques-Normark B, Axelsson LG, Midtvedt T, Putsep K, et al. Secreted enteric antimicrobial activity localises to the mucus surface layer. Gut (2008) 57:764-71. doi:10.1136/gut.2007.141481

84. Dupont A, Kaconis Y, Yang I, Albers T, Woltemate S, Heinbockel L, et al. Intestinal mucus affinity and biological activity of an orally administered antibacterial and anti-inflammatory peptide. Gut (2014) 7:2014. doi:10.1136/gutjnl-2014307150

85. Burger-van Paassen N, Loonen LM, Witte-Bouma J, Korteland-Van Male AM, De Bruijn AC, Van Der Sluis M, et al. Mucin Muc2 deficiency and weaning influences the expression of the innate defense genes Reg3beta, Reg3gamma and angiogenin-4. PLoS One (2012) 7:e38798. doi:10.1371/journal. pone. 0038798

86. Birchenough GM, Johansson ME, Stabler RA, Dalgakiran F, Hansson GC, Wren BW, et al. Altered innate defenses in the neonatal gastrointestinal tract in response to colonization by neuropathogenic Escherichia coli. Infect Immun (2013) 81:3264-75. doi:10.1128/IAI.00268-13

Conflict of Interest Statement: The authors declare that the research was conducted in the absence of any commercial or financial relationships that could be construed as a potential conflict of interest.

Received: 14 July 2014; accepted: 16 September 2014; published online: 09 October 2014.

Citation: Hornef MW and Fulde $M$ (2014) Ontogeny of intestinal epithelial innate immune responses. Front. Immunol. 5:474. doi: 10.3389/fimmu.2014.00474

This article was submitted to Immunotherapies and Vaccines, a section of the journal Frontiers in Immunology.

Copyright (c) 2014 Hornef and Fulde. This is an open-access article distributed under the terms of the Creative Commons Attribution License (CC BY). The use, distribution or reproduction in other forums is permitted, provided the original author (s) or licensor are credited and that the original publication in this journal is cited, in accordance with accepted academic practice. No use, distribution or reproduction is permitted which does not comply with these terms. 